Article

\title{
Treatment of Coal Fly Ash and Environmentally Friendly Use with Rubber in Cable Wires as Insulation Material
}

\author{
Zawar Hussain, Gao Lizhen * and Muhammad Moeen
}

College of Environmental Science and Engineering, Taiyuan University of Technology, Taiyuan 030000, China; hussain.zawar1292@hotmail.com (Z.H.); moeenejaz79@gmail.com (M.M.)

* Correspondence: gaolizhen@tyut.edu.cn

Received: 25 May 2020; Accepted: 22 June 2020; Published: 26 June 2020

check for updates

\begin{abstract}
Energy demand is increasing all over the world, and to fulfill this need, more energy is required to be produced. Coal power plants produce around 39\% of energy, but during energy production, these coal power plants also generate waste in the form of coal fly ash (CFA). The reuse of CFA is the only solution to control this waste; fly ash can be used in different products. Therefore, this study utilizes CFA with rubber as filler materials in the rubber industry. There are different techniques (such as nozzle design technology, air classifier, and optimization of CFA to convert crushed fly ash into valuable microparticles. Treated CFA is applied to produce medium voltage insulated cables and fire resistance cables with different kinds of rubber, such as styrene-butadiene and Ethylene-propylene. The study found that by applying CFA in insulated cables, the elongation at break increased by $50 \%$, and volume resistance $2.2 \times 10^{16} \Omega \cdot \mathrm{cm}$, insulation resistance increased $70 \%$ by using CFA with magnesium in the recipe of insulated cables. The CFA increased the collection rate of cleaning by $30 \%$ using this technology, and product life expectancy increased by $5-20 \%$.
\end{abstract}

Keywords: coal fly ash; microparticle; insulated cable; fire resistance cable; volume resistance; magnesium; insulation

\section{Introduction}

Coal is of the world's primary source of electricity supply, demonstrating a drastic increase in its consumption. However, coal combustion has significant effects on human health and climate change [1,2]. Generally, $5-12 \%$ of the total coal persists un-blistered and is deposited as a dense layer of small particles, usually referred to as fly ash [3], a general name of all forms of byproducts, such as coal fly ash (CFA), formed during coal combustion [4]. Regardless of the current efforts to develop alternative energy sources, coal is expected to remain in the predictable prospect as the primary source of global power production, accounting for around $40 \%$ worldwide $[5,6]$. China is the largest coal consumer, accounting for approximately $40 \%$ of the overall world consumption in recent decades, followed by the European Union (EU), the United States (US), and India at 10\%, 18\%, and 8\%, respectively $[7,8]$.

Coal fly ash (CFA) manufactured as waste material derived from coal from power stations is considered a problematic solid waste worldwide [9]. Earlier literature estimated that CFA production globally is more than 500 million tons annually. Notably, in China, due to rapid economic development, the consumption of coal has been boosted by $50 \%$ [2]. A ubiquitous proportion of CFA produced annually is disposed of in those countries where its production is maximum, i.e., China, India, and the US [4]. It has been disposed of for many decades by diverting the ash into landfills known as ash lagoons. Ash lagoons have been known to breach and cause severe ecosystem and environmental 
constraints [2]. Environmental hazards and stricter legislation are increasing the costs of disposing of CFA in ash lagoons [10,11]. The yearly production in tons and utilization percentage of CFA in different countries is shown in Figure 1.
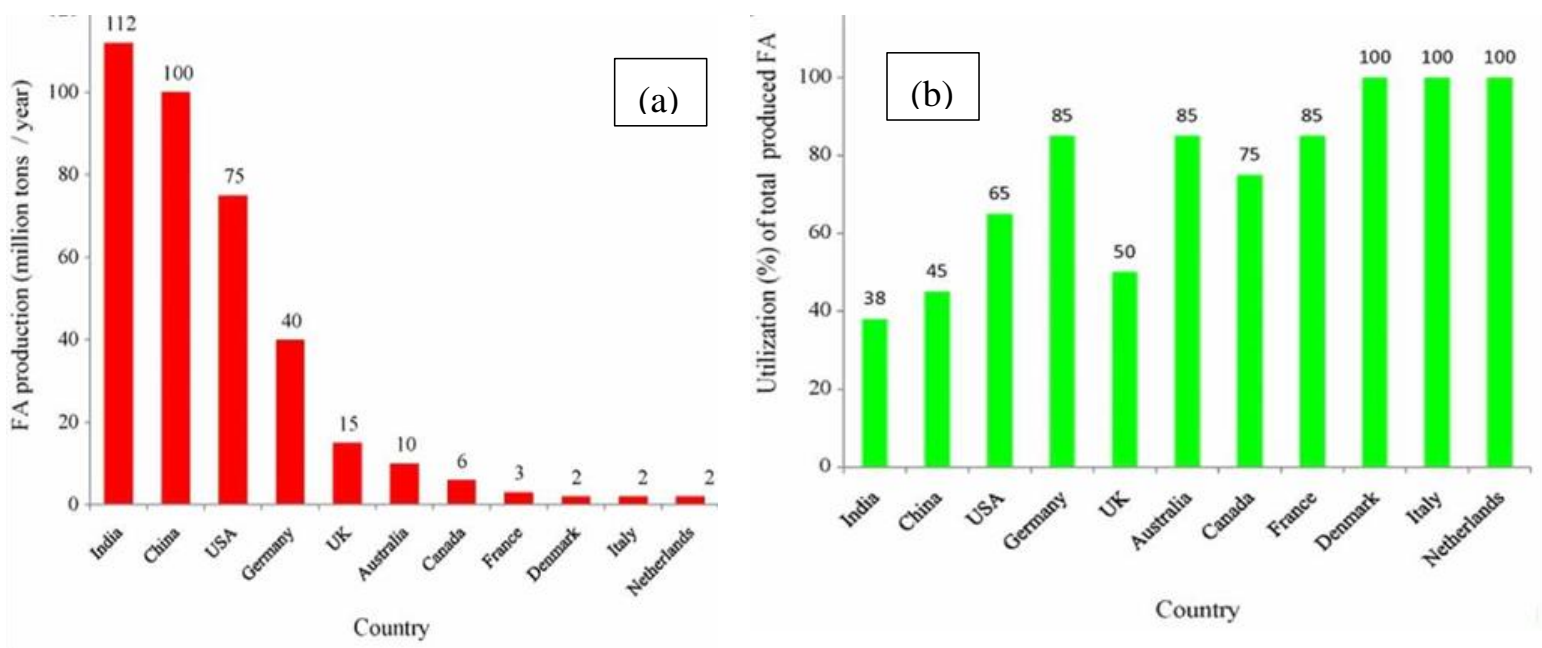

Figure 1. (a) Fly ash production (million tons/year) in different countries, (b) utilization (\%) of the total produced fly ash in different countries.

Physiological and chemical attributes of CFA differ significantly depending on the basis and type of coal, combustion temperature, combustion process, fuel/air ratio, and feed coal particle size [12]. The key mechanism of CFA samples is enriched with aluminum oxides, silica, and iron with different amounts of carbon content as a loss on ignition (LOI), calcium oxide and magnesium oxide $[13,14]$. Higher content of magnesium and calcium oxide and lower contents of oxide of silica, iron, and aluminum are present in sub-bituminous and lignite CFA compared to bituminous CFA.

CFA can be significantly employed as a rubber filler [15], with a large fraction of precipitated silica [16], creating rubber compounds of maximum mechanical characteristics [17]. The mechanical attributes of styrene-butadiene rubber (SBR) can increase with fly ash [18]. It was found that when contrasted with carbon black filled SBR, CFA has a significant reinforcing impact in raising elongation, modulus, and strength of the rubber compound [19].

Over the last few years, silicon rubber and epoxy resin have demonstrated great potential in industry because they are used as an alternative material to ceramic and glass due to their properties, such as dielectric, volume resistivity, mechanical strength, thermal conductivity, and lightweight $[20,21]$. Due to their lightness, they are easier to use and control than other ceramic and glass materials. Furthermore, polymer insulator, especially silicone rubber, is a hydrophobic material. It has water repellent properties and also can be used as an outdoor insulator. Especially in rainy weather, the hydrophobic properties of silicon rubber have the benefit of preventing the leakage of current because of the low conductivity of the insulation [22].

Styrene-butadiene rubber demonstrates strong abrasion tolerance and flexibility in rubber industries, that is why SBR is widely used in tire treading [23]. The synthesis of SBR was the first rubber produced commercially with the help of the Ziegler-Natta catalyst and was generated in the middle of the last century $[18,24]$. SBR is formed in a hydrocarbon solution, including initiators, and develops a large molecular weight with small distribution by living polymerization.

\section{Objectives}

1. Treatment of CFA with different pulverization technologies to make useable nanoparticles;

2. Fly ash applied to medium voltage insulated cables (instead of filling the main material);

3. Fly ash applied to inorganic fire-resistant cables (instead of filling the main material). 


\section{Materials and Methods}

\subsection{Treatment of Coal Fly Ash (CFA)}

Fly ash is not waste but an available resource that is used in many countries after treatment to add value. The particle size of fly ash directly determines the product object, sales radius, and price generated by it. Therefore, it is necessary to treat CFA for further use to produce valuable products. The whole procedure of treatment and utilization of fly ash is shown in Figure 2. Various methods used to treat CFA are following.

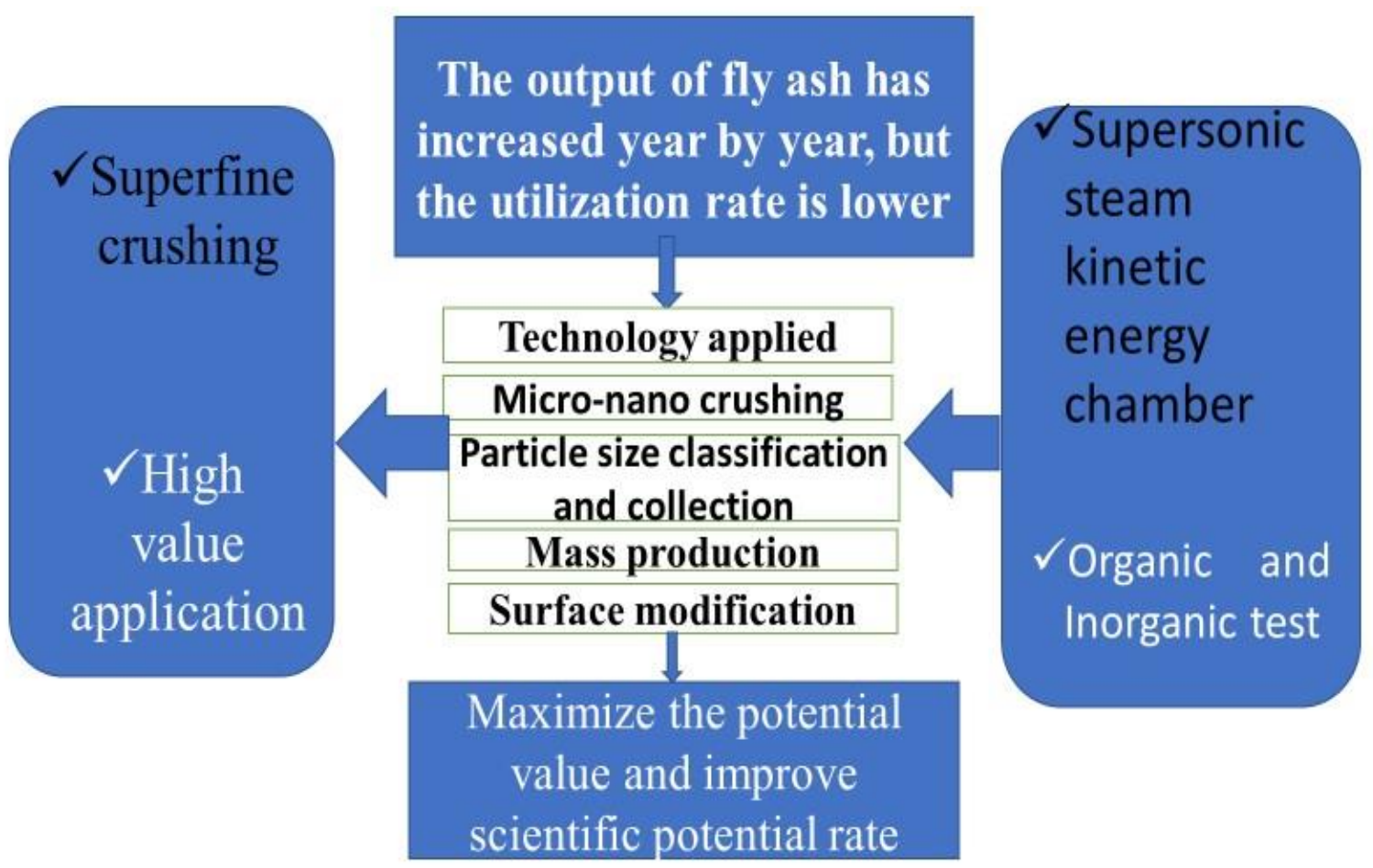

Figure 2. Core technology roadmap of coal fly ash.

\subsubsection{Nozzle Design Technology Based on Micro-Expansion Theory}

Nozzle design technology pulverization takes place on two steps. In the first step, different sized nozzles are used to produce finer sized particles of CFA [1], with different pressures and velocities applied for different nozzles. One side of the nozzle produces pressure, and CFA particles move with different velocities and pass through the different sized nozzles. Another method, the nozzle back spray technology, is more efficient. In this method, water vapors spread by a nozzle through the passed-out particles of CFA. Induction back nozzle technology is the automatic method of collecting and separating finer particles of CFA by different densities. The graphical detail of this technology is shown in Figure 3.

\subsubsection{Air Classifier}

Air classifier used for the separation and extraction of bead particles of CFA. Fly ash was collected in a big chamber of the classifier. Air pressure was provided by an air pump to separate CFA particles. Furthermore, coal ash particles traveled through four different chambers, and different sized bead particles were collected and coated by these four chambers. The impacting ratio reached more than $98 \%$ by using this classifier machine without destroying the particle morphology $[25,26]$. This modifier machine was used for a small quantity of CFA, and can be applied to various modifiers. By using this technique, the efficiency rate increases, there is low wear and higher precision, and it can grade D97 = 3-75 $\mu \mathrm{m}$ fine powder. 


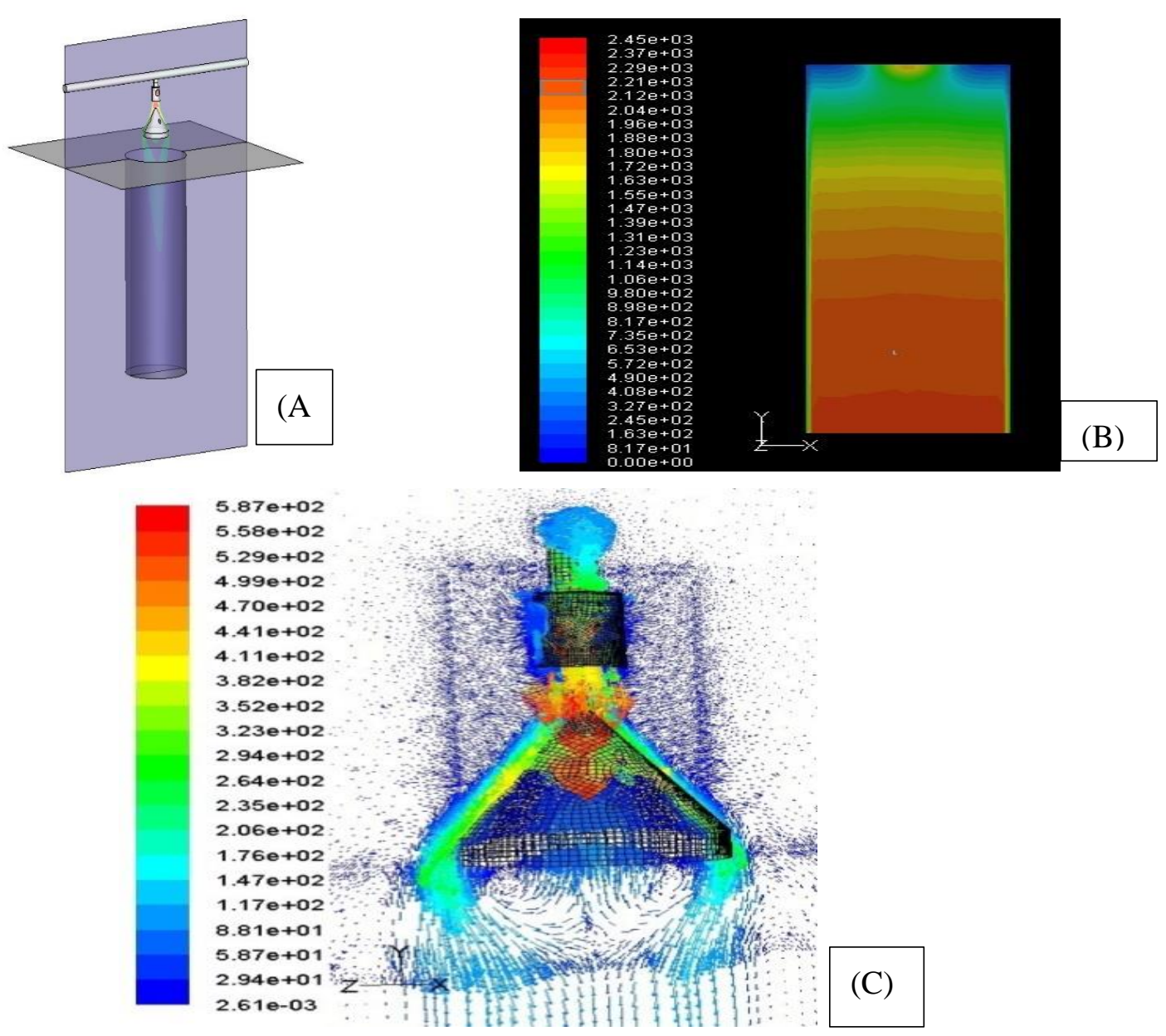

Figure 3. Graphical details of induction nozzle back-spray technology (A-C).

\subsubsection{Optimization of Coal Fly Ash by Static Pressure and Velocity}

The optimization of CFA showed the difference between static pressure of fly ash size and different velocity. Scanning electron microscopy (SEM) X-ray diffraction showed four different kinds of CFA produced on the basis of size [2]. Figure 4 explains the static pressure and size of CFA produced, and velocity applied to reduce the size of particles. SEM results showed that more static pressure decreased the size of CFA and increased the $300 \mu \mathrm{m}$ size production of CFA [27]. Different pressures showed different peaks of particle size. The highest peak showed the highest value of pressure $180 \mathrm{kPa}$ and particle size $300 \mu \mathrm{m}$ produced on this highest peak of pressure. Similarly, the velocity size particle graph shows that the highest peak of velocity was near $1200\left(\mathrm{~ms}^{-1}\right)$. On this peak particle size, $380 \mu \mathrm{m}$, production increased more than $300 \mu \mathrm{m}$ sized particles. X-ray diffraction results showed that particle size result varies with different pressures and velocities; the production of nanoparticles increased at high pressure instead of velocity and effectively reduced energy consumption and reduced turbulence in the material chamber.

\subsection{Properties of Fly Ash}

Different coal-fired power generation processes produce different fly ash, which is divided into low-temperature fly ash and high-temperature fly ash. The high-temperature pulverized CFA temperature was $1400{ }^{\circ} \mathrm{C}-1600{ }^{\circ} \mathrm{C}$ of power generation, and low-temperature CFA was produced by $800{ }^{\circ} \mathrm{C}-900{ }^{\circ} \mathrm{C}$ of power generation. The physical properties, chemical composition, and mineral composition of different fly ash were different. It depended on different ways of use, different ultra-fine processes [3]. A low-temperature fluidized bed can form irregular sheet-like and laminated structures, 
and then be crushed and classified to form a finer micron-sized and more granular structure so that it can be used in various industrial materials. Table 1 shows the physical and chemical composition of low-temperature and high-temperature CFA. Figure 5 shows an anomalous flakes' magnification graph by SEM of low-temperature CFA and high-temperature CFA. Figure 6 shows packed nana beads by SEM magnification (3500x) of high-temperature produced CFA. The fly ash of the microbead structure was light in weight, and the porous adsorption property had the properties of insulation, high-temperature resistance, wear resistance, heat preservation, heat insulation, and aging resistance, and had excellent characteristic materials and is widely used.

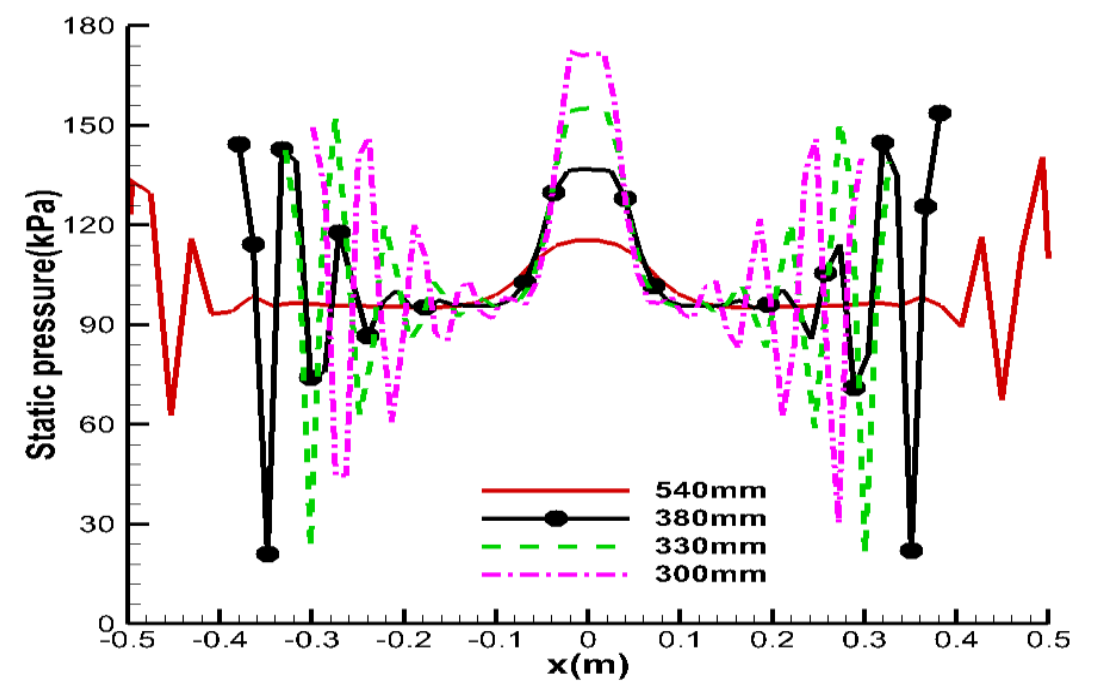

(A)

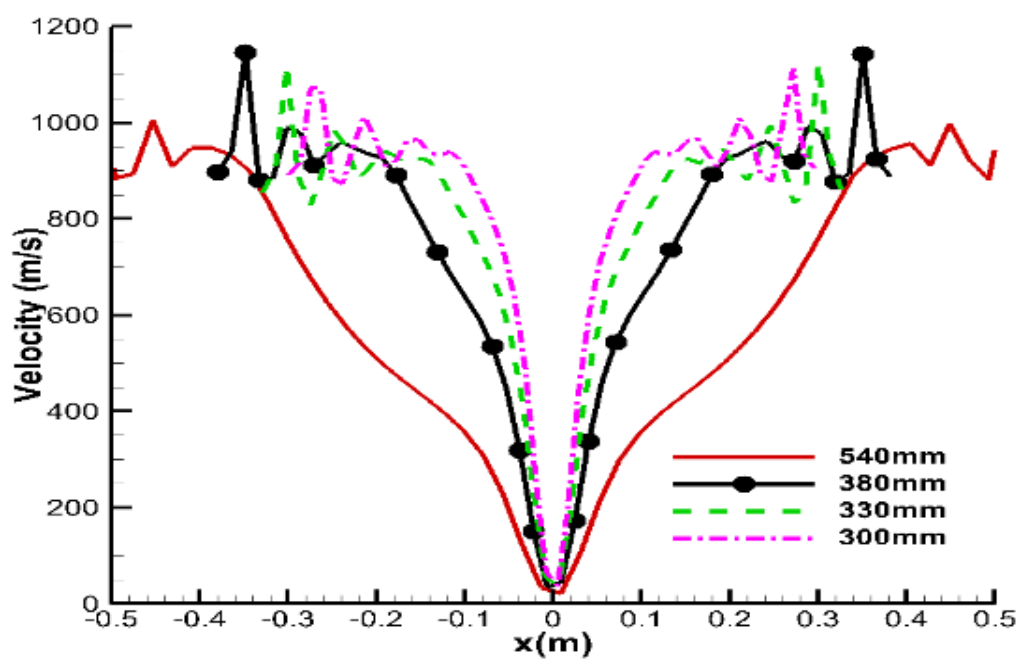

(B)

Figure 4. Optimization of coal fly ash particles by SEM X-ray diffraction of static pressure (A) and velocity (B).

\subsection{Application of Coal Fly Ash in the Manufacturing of Medium Voltage Insulated Cables}

Coal fly ash can be used as filler material instead of other materials, such as coal and quartz, in the manufacturing of medium voltage insulated cables. The recipe used for this production was ethylene-propylene rubber (Dow 3722P,) + vulcanizing agent DCP3.5 + cross-linking agent TAIC2.2 + fly ash (D97-10 microns) + stearic acid + zinc oxide + paraffin. This formula was designed for a 
medium-voltage rating $(6000 \mathrm{~V})$. Medium-voltage insulated cables have two parts one is a copper conductor which transforms the electrical current, and the other part is insulation parts of the cable. This part protects the conductor and increases the lifetime of the conductor and cables. This study was conducted to produce the insulation part of the cables using the above-mentioned recipe. The insulation part was further divided into the covering part, which was also produced by the above-mentioned formula. Different kinds of filler materials, such as coal gangue, clay, quartz powder, and fly ash, was used to produce insulation material of medium voltage cables. The vulcanization process was done at different temperatures for different types of filler materials in 16 minutes. D97-10 modified micro nanocrystals of CFA were used for the insulation material of the cable. After the completion of the vulcanization process and cooling at room temperature to harden, different tests were applied to compare the CFA made product with other expensive material products.

Table 1. Physical and chemical composition on different temperature coal fly ash.

\begin{tabular}{ccc}
\hline Chemical Composition & $\begin{array}{c}\text { Content }(\% \text { by Weight) Produced } \\
\text { at High Temperature }\end{array}$ & $\begin{array}{c}\text { Content (\% by Weight) Produced } \\
\text { at Low Temperature }\end{array}$ \\
\hline Burn down & 0.84 & 2.45 \\
Aluminum oxide $\mathrm{Al}_{2} \mathrm{O}_{3}$ & 41.85 & 36.12 \\
Silica $\mathrm{SiO} 2$ & 46.22 & 47.67 \\
Ferric oxide $\mathrm{Fe}_{2} \mathrm{O}_{3}$ & 3.97 & 5.59 \\
Calcium Oxide $\mathrm{CaO}$ & 3.51 & 4.91 \\
Magnesium oxide $\mathrm{MgO}$ & 0.57 & 0.84 \\
Potassium oxide $\mathrm{K}_{2} \mathrm{O}$ & 0.37 & 0.42 \\
Sodium oxide $\mathrm{Na}_{2} \mathrm{O}$ & 0.15 & 0.01 \\
Titanium dioxide $\mathrm{TiO}_{2}$ & 1.76 & 1.51 \\
Amorphous & 60 & 60 \\
Quartz $\mathrm{SiO}_{2}$ & 8 & 8 \\
Mullite $3 \mathrm{AI}_{2} \mathrm{O}_{3} .2 \mathrm{SiO}_{2}$ & 28 & 28 \\
Feldspar & 4 & 4 \\
Other & 3 & 3 \\
\hline
\end{tabular}

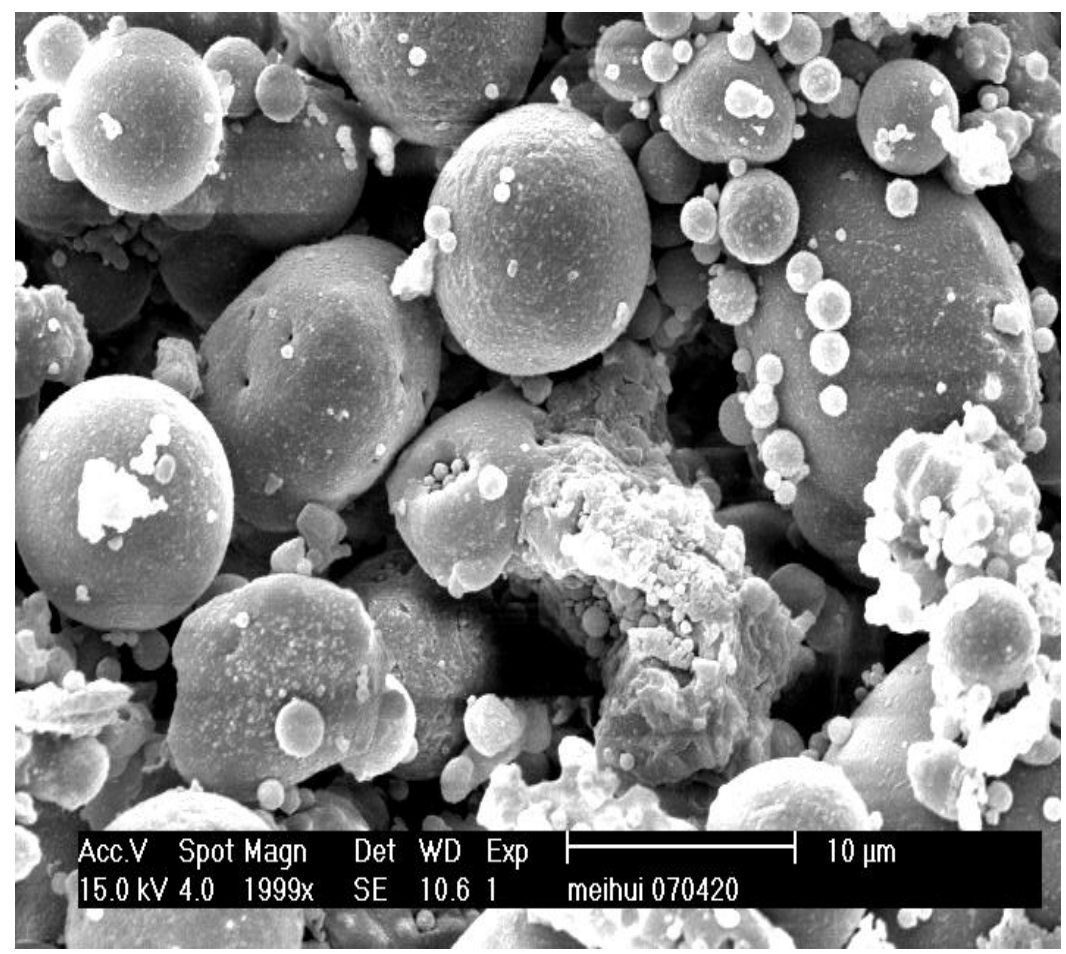

Figure 5. SEM magnification of low-temperature CFA. 


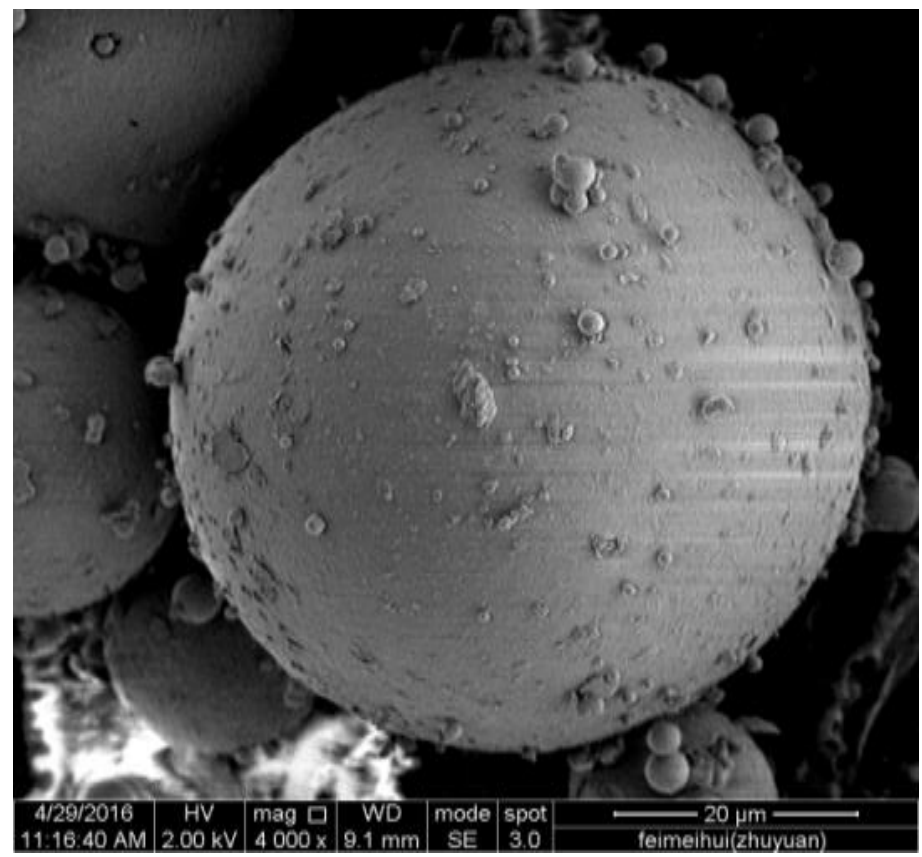

Figure 6. SEM magnification of high-temperature CFA.

\subsubsection{Thickness of Medium Voltage Cables}

A digital Vernier caliper was used to measure the thickness of the insulation part of the medium voltage cable; the cross-sectional area of the insulated material was measured in $\mathrm{mm}$. Different filler material manufactured cables were measured one by one and compared with the fly ash made insulation part. The cross-sectional area equation measures the thickness of medium voltage by measuring the diameter of the insulated part of the cable by following Equation (1).

$$
\mathrm{S}=\pi \mathrm{R}^{2}
$$

where $S$ is the thickness of the medium voltage cable, the $\pi$ value used is $3.14, R$ is the radius of tested cable, which is measured by a Vernier caliper.

\subsubsection{Tensile Strength and Elongation at Break}

The tensile strength of the medium voltage cable was the force to pull the cable at the point of breakdown of the cable. The elongation of the cable was the stretched point before the breakdown of the cable. The tensile strength of the medium voltage cable was measured without a conductor; the insulated part of the cable was tested. A testometric was applied to test the elongation at break and tensile strength. The tested cables to be marked into two points with $20 \mathrm{~mm}$ length. The force applied to breakdown the cables was measure in $\mathrm{MPa}$, and the stretched points were also measured in $\%$. Test results shown on the screen connected with the tensile testometric machine.

\subsubsection{Volume Resistivity (VR)}

The volume resistance (VR) test confirmed a material of low enough resistance test to function appropriately in a medium insulated cable. A cable sample was placed in the test machine, and all electrodes were covered. Then the testing machine was closed. Readings of the tested cables appeared in volts and amps by ammeter and voltmeter. Further results were calculated by the following equation:

$$
\mathrm{VR}=\frac{v}{A} \mathrm{TF}=\text { value } \Omega \cdot \mathrm{cm}
$$


where VR is the volume resistivity of cable, $\mathrm{v}$ is the volts of electric current passed through the cables, $A$ is the amps of the cable, and TF is the thickness factor of the medium voltage cable.

\subsection{Application of Coal Fly Ash in the Manufacturing of Fire-Resistant Cables}

Fire resistance cables are used to protect fire to spread, high-temperature resistance, corrosion resistance, water resistance, and protection from short circuits. Fire resistance cables contain a fire retardant insulation part and a conductor part to conduct the electric current [28]. Coal fly ash was used to manufacture the fire-retardant insulation part of fire resistance cables instead of other filler materials, such as calcined high-pressure clay, medium pressure clay, low-pressure clay, Maoming washed calcined clay, and quartz powder.

The vulcanization process takes place to produce the insulation part of the cables by different materials. The insulation part contains cross-linked polyethylene (XLPE), cross-linked ethylene-vinyl acetate (XLEVA), ethylene-propylene rubber (EPR), polyethylene (PE), and polyvinyl chloride (PVC) [29]. The mixture of these materials was mixed with different filler materials, such as magnesium, kaolin, talcum powder, magnesium oxide, and treated CFA. These materials were used for bonding of the insulation part of the cable and to make a solid fire-resistance cover sheath of the cable to protect it from fire. Different filler materials were used to produce fire resistance cables and compared with different tests with the CFA filler material in the production of the cables. Fire resistance cables are mostly used in hospitals, airports, and other important buildings.

Different tests were applied to check the quality of fire resistance tests and a comparison of different filler materials used in the vulcanization process of $64 \mathrm{~m}$ produced cable was made. First of all, the exterior of the cable was checked to confirm the defect in the laboratory manufactured fire resistance cable, and then, an immersion test with water at room temperature for one hour was applied to check the corrosion damage. All the filler material-produced cables were tested and compared with CFA filler production cables. The copper sheath outer diameter was checked with the help of a digital Vernier caliper, and results were noted; same as for the medium voltage test. Another test applied was the DC resistance of the copper sheath used in fire resistance cables. A DC resistance digital micro-ohm meter was used to check the DC resistance in the lab. Values of the test were calculated by the following formula of DC resistance:

$$
\mathrm{R}=\frac{\rho 20}{\mathrm{~S}}
$$

where $\mathrm{R}$ is the DC resistance of the fire resistance cable, $\rho 20$ is the electrical resistivity of the conductor material at $20^{\circ} \mathrm{C}$ temperature, $S$ is the cross-sectional area of the conductor. The $\mathrm{R}$ value was calculated by this formula using the SI $\Omega$ unit. Insulation material thickness of the produced cables was also measured one by one by a digital Vernier caliper. Another test applied to the fire resistance cable was conductor continuity, to check the continuity of the conductor multimeter. Two conductors of the multimeter were connected with the testing wires one by one with different conductor wire to check the continuity of wire conductors. Another important test for electrical safety testing is the insulation resistance test. The insulation resistance test was done by a tera ohm meter tester (megger meter). The value shown on the screen of the meter by testing insulation resistance tests was the measured value of resistance that had to be higher than the international standard value.

Another test applied to test cable was the withstand voltage test. Actually, this test is a high voltage test of the cable conductor. A high voltage was passed through the cable to check the insulator quality to see if the current passed through without damaging the insulation part of the cable. This test evaluates the quality of the insulation material present on the conductors. Two point five kilovolt was applied to the all manufactured wires using different filler materials for 1 minute to check the voltage test. The average thickness of the copper sheath was also measured and compared with the international standard. 


\section{Results}

\subsection{Fly Ash Applied to Medium Voltage Insulated Cable (Instead of Filling Main Material)}

Table 2 shows the physical tests' results of the insulated cable and compares fly ash with different expensive filler materials. The vulcanization time for this formula with different materials was the same-16 minutes, using coal gangue 850-degree calcined high-pressure clay (CGCHPC). In the above-mentioned formula, the thickness of the insulated cable was $1.45 \mathrm{~mm}$, tensile strength was 8.46 MPa, elongation of break was $247.65 \%$, and VR was $2.9 \times 10^{16} \Omega \mathrm{cm}$. Another filler material was coal-based calcined high-pressure clay (CBCHPC), which was used in the above-mentioned recipe of medium voltage insulated cable. Data showed that the thickness was $1.3 \mathrm{~mm}$, tensile strength $9.51 \mathrm{MPa}$, elongation at break $241.3 \%$, and VR was $2 \times 10^{16} \Omega \mathrm{cm}$. The third filler material was 700 -degree medium pressure clay (MPC). Results showed that the thickness of the insulated cable value was $1.4 \mathrm{~mm}$, tensile strength was $8.73 \mathrm{MPa}$, elongation at break was $276.18 \%$, and VR was $3 \times 10^{16} \Omega \mathrm{cm}$.

Another filler material used in the above-mentioned formula was 980-degree low-pressure clay (LPC). By using this filler material, the thickness of the insulated cable was $1.4 \mathrm{~mm}$, tensile strength was $8.57 \mathrm{MPa}$, elongation at break was $250.22 \%$, and VR value was $1.7 \times 10^{16} \Omega \cdot \mathrm{cm}$. Maoming washed calcined clay (MWCC) was also used as a filler material in the above formula for the production of medium voltage insulated cable. Using this filler material, results showed that the thickness was $1.3 \mathrm{~mm}$, tensile strength was $5.11 \mathrm{MPa}$, elongation at break was $240.52 \%$, and volume resistivity was $2.7 \times 10^{16} \Omega \cdot \mathrm{cm}$. Another main material that was used as an alternative material in the above formula for the making of insulated cable was treated CFA. By using D97-10 micron CFA in this product, the test result data showed that the thickness of the insulated cable was $1.3 \mathrm{~mm}$, tensile strength was $8.12 \mathrm{MPa}$, elongation at break was $334.82 \%$, and VR was $2.2 \times 10^{16} \Omega \cdot \mathrm{cm}$. The final and last filler material was quartz fine powder 3500 eyes (QFP), which was used in the above-mentioned recipe. According to this recipe, results showed that the thickness of the insulated cable was $1.4 \mathrm{~mm}$, tensile strength was $4.9 \mathrm{MPa}$, elongation at break was $378.41 \%$, and VR was $2.7 \times 10^{16} \Omega \cdot \mathrm{cm}$.

\subsection{Fly Ash Applied to Inorganic Fire-Resistant Cables (Instead of Filling Main Materials)}

Table 3 shows the different test results of inorganic fire-resistant cables. The immersion test was applied to check the corrosion for all four kinds of cables passed through this test, including fly ash and magnesium oxide filler-used cables. Exterior and voltage tests were also the same for four different filler products of cables, but the inspection results were different, which were tested by the national standard. In detail, the results found that magnesium and kaolin magnesia filler qualified for this test, but talcum powder and magnesium oxide filler failed. And fly ash and magnesium oxide results were found to be the best rather than the other three fillers.

The results showed that by using magnesium as the filler material, the different tests data were an outer diameter of copper sheath of $18.32 \mathrm{~mm}$, copper sheath DC resistance at $20{ }^{\circ} \mathrm{C}$ of $0.479 \Omega$, minimum insulation thickness of $0.93 \mathrm{~m}$, conductor DC resistance of the wire at $20^{\circ} \mathrm{C}$ temperature of $0.116 \Omega$, insulation resistance of $12,100 \mathrm{M} \Omega$, and an average thickness of the copper sheath of $0.93 \mathrm{~mm}$. As well when using kaolin and magnesium as the filler material in the formation of insulated cables, the test result showed that the outer diameter of the copper sheath was $18.35 \mathrm{~mm}$, copper sheath DC resistance at $20^{\circ} \mathrm{C}$ was $0.498 \Omega$, minimum insulation thickness was $0.93 \mathrm{~m}$, conductor DC resistance of the wire at $20{ }^{\circ} \mathrm{C}$ temperature was $0.116 \Omega$, insulation resistance was $10,000 \mathrm{M} \Omega$, and average thickness of the copper sheath was $0.93 \mathrm{~mm}$. The other filler materials used in the formation of insulated cable were talcum powder and magnesium oxide. Results showed that the outer diameter of the copper sheath was $17.98 \mathrm{~mm}$, copper sheath DC resistance at $20^{\circ} \mathrm{C}$ was $0.392 \Omega$, minimum insulation thickness was $0.91 \mathrm{~m}$, conductor DC resistance of the wire at $20^{\circ} \mathrm{C}$ temperature was $0.112 \Omega$, insulation resistance was $9800 \mathrm{M} \Omega$, and average thickness of the copper sheath was $0.95 \mathrm{~mm}$. 
Table 2. Comparison of fly ash with different materials used in medium voltage insulated cables.

\begin{tabular}{|c|c|c|c|c|c|}
\hline Main Material & $\begin{array}{l}\text { Vulcanization } \\
\text { Time }\end{array}$ & Thickness (mm) & $\begin{array}{l}\text { Tensile Strength } \\
\text { (MPa) }\end{array}$ & $\begin{array}{c}\text { Elongation at Break } \\
(\%)\end{array}$ & $\begin{array}{c}\text { Volume Resistivity } \\
(\Omega \cdot \mathrm{cm})\end{array}$ \\
\hline $\begin{array}{l}\text { Coal gangue 850-degree calcined } \\
\text { high-pressure clay (CGCHPC) }\end{array}$ & $16 \mathrm{~min}$ & 1.45 & 8.46 & 247.65 & $2.9 \times 10^{16}$ \\
\hline $\begin{array}{l}\text { Coal-based calcined high-pressure clay } \\
\text { (refining type) (CBCHPC) }\end{array}$ & $16 \mathrm{~min}$ & 1.3 & 9.51 & 241.3 & $2 \times 10^{16}$ \\
\hline 700-degree medium pressure clay (MPC) & $16 \mathrm{~min}$ & 1.4 & 8.73 & 276.18 & $3 \times 10^{16}$ \\
\hline 980-degree low pressure clay (LPC) & $16 \mathrm{~min}$ & 1.4 & 8.57 & 250.22 & $1.7 \times 10^{16}$ \\
\hline Maoming washed calcined clay (MWCC) & $16 \mathrm{~min}$ & 1.3 & 5.11 & 240.52 & $2.7 \times 10^{16}$ \\
\hline $\begin{array}{l}\text { Fly ash D97-10 micro nano } \\
\text { crystallization, modification }\end{array}$ & $16 \mathrm{~min}$ & 1.3 & 8.12 & 334.82 & $2.2 \times 10^{16}$ \\
\hline Quartz fine powder 3500 eyes (QFP) & $16 \mathrm{~min}$ & 1.4 & 4.9 & 378.41 & $2.7 \times 10^{16}$ \\
\hline
\end{tabular}

Table 3. Comparison of technical indicators in refractory fire resistance cables (testing items after drawing into the cable).

\begin{tabular}{|c|c|c|c|c|c|}
\hline \multicolumn{6}{|c|}{$\begin{array}{c}\text { Model, Specification }\left(\mathrm{mm}^{2}\right) \text { BTTZ 1*150 Voltage Class (V) } 750 \\
\text { Testing Base GB/T13033.-1-2007 Standard }\end{array}$} \\
\hline Test Applied & $\begin{array}{l}\text { Standard Requirements } \\
\text { (National Standards) }\end{array}$ & Magnesium & Kaolin, Magnesia & $\begin{array}{c}\text { Talcum Powder, } \\
\text { Magnesium Oxide }\end{array}$ & $\begin{array}{c}\text { Fly Ash, Magnesium } \\
\text { Oxide }\end{array}$ \\
\hline Exterior & Gardening, no defects & Conform & Conform & Conform & Conform \\
\hline Immersion test & $\begin{array}{l}\text { Immersed in water for } 1 \mathrm{~h} \\
\text { at room temperature }\end{array}$ & Passed through & Passed through & Passed through & Passed through \\
\hline Copper sheath outer diameter & $18.4 \pm 0.05 \mathrm{~mm}$ & 18.32 & 18.35 & 17.98 & 18.37 \\
\hline $20{ }^{\circ} \mathrm{C}$ copper sheath DC resistance & $\leq 0.479 \Omega$ & 0.479 & 0.498 & 0.392 & 0.386 \\
\hline Minimum insulation thickness & $0.94 \mathrm{~m}$ & 0.93 & 0.93 & 0.91 & 0.93 \\
\hline Conductor continuity & Conduction & via & via & via & Via \\
\hline $20{ }^{\circ} \mathrm{C}$ conductor DC resistance & $\leq 0.124 \Omega$ & 0.116 & 0.116 & 0.112 & 0.117 \\
\hline $\begin{array}{c}\text { Insulation resistance } \\
\geq 10,000 \mathrm{M} \Omega\end{array}$ & $\geq 10,000 \mathrm{M} \Omega$ & $12,100 \mathrm{M} \Omega$ & $10,000 \mathrm{M} \Omega$ & $9800 \mathrm{M} \Omega$ & $\begin{array}{l}13,900 \mathrm{M} \Omega \\
\text { highest! }\end{array}$ \\
\hline Withstand voltage test & $2.5 \mathrm{kV} / 1 \mathrm{~min}$ & via & via & via & via \\
\hline Average thickness of copper sheath & $0.90 \mathrm{~mm}$ & 0.93 & 0.93 & 0.95 & 0.93 \\
\hline $\begin{array}{l}\text { Inspection results: } \\
\text { GB/13033.1-2007 standard }\end{array}$ & $\begin{array}{l}\text { National standard } \\
\text { requirements }\end{array}$ & qualified & qualified & failed & the best \\
\hline
\end{tabular}


The other main material which was used in the formation of insulated cable instead of talcum powder with magnesium oxide was CFA. Results showed that by using CFA, the outer diameter of copper sheath was $18.37 \mathrm{~mm}$, copper sheath DC resistance at $20^{\circ} \mathrm{C}$ was $0.386 \Omega$, minimum insulation thickness was $0.93 \mathrm{~m}$, conductor $\mathrm{DC}$ resistance of the wire at $20^{\circ} \mathrm{C}$ temperature was $0.117 \Omega$, insulation resistance was $13,900 \mathrm{M} \Omega$, and average thickness of the copper sheath was $0.93 \mathrm{~mm}$.

\section{Discussion}

Figure 7 shows different test results of medium insulated cables. The results for the thickness (Figure 7A.) of insulated cables by using different materials and compared with CFA, showed that the highest thickness recorded was $1.45 \mathrm{~mm}$ using coal gangue 850-degree calcined high-pressure clay (CGCHPC). Results of the three materials, including fly ash $(1.3 \mathrm{~mm})$, were the same as $1.4 \mathrm{~mm}$, but CFA is a waste material and cheaper than other materials used. CFA-produced insulation material of cable thickness comparable with other filler material thicknesses. Figure 7B shows the tensile strength results of the insulated cables using different materials in the recipe. The highest tensile strength was 9.51 MPa shown by using coal-based calcined high-pressure clay (CBCHPC), and the lowest value was 4.9 MPa by using quartz fine powder (QFP). Using fly ash D97-10 micron, the result of the tensile strength test value was $8.12 \mathrm{MPa}$, which is acceptable and better than other filler materials, such as Maoming washed calcined clay (MWCC) and quartz fine powder 3500 eyes (QFP). Thus, results found that the fly ash filler insulation part of the medium voltage cable breakdown was at the $8.12 \mathrm{MPa}$ point. At $30 \mathrm{phr}$, fly ash composition showed that tensile strength and elongation at break had a good result in the rubber matrix. The rubber matrix bond increased not just due to temperature but also with increased fly ash quantity [30].

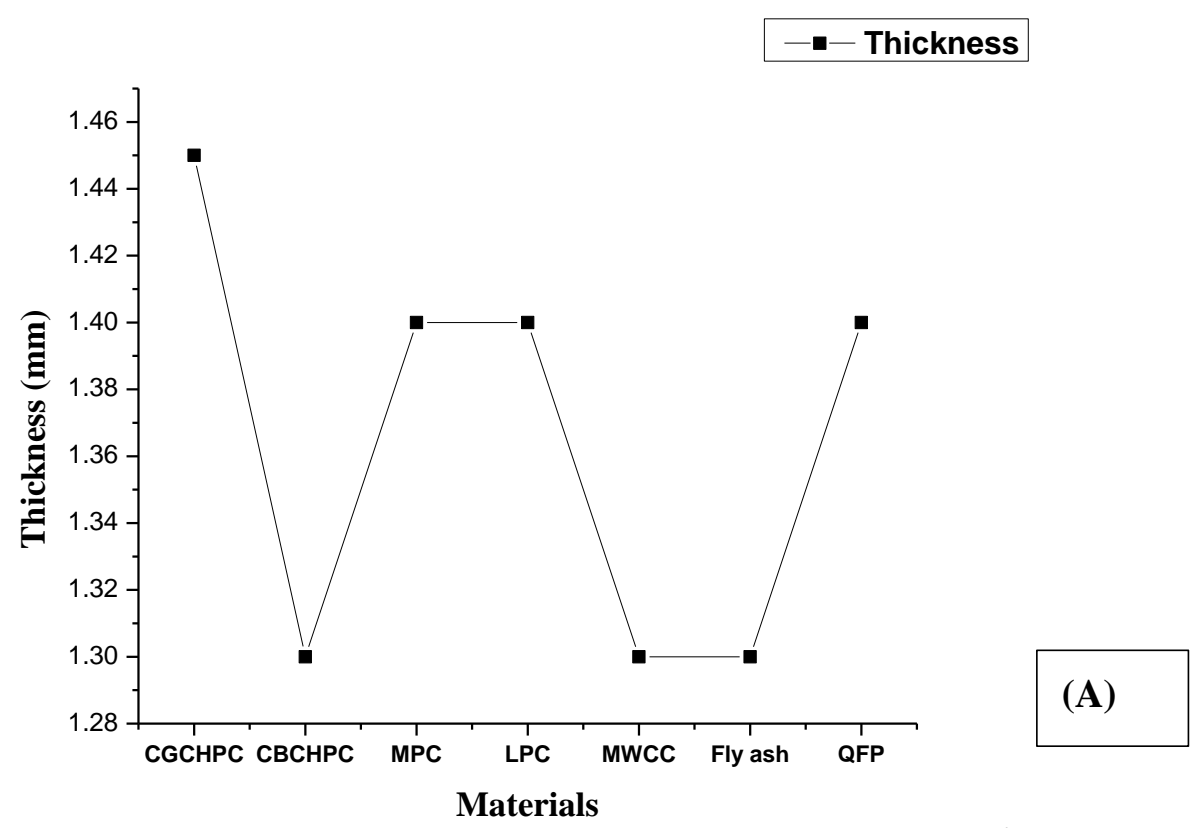

Figure 7. Cont.

Figure 7C shows the results of elongation at break of insulated cable. This is an important test of any cable. If a cable cannot tolerate stretching and is damaged quickly, that cable is not safe and electric current can leak out. The results showed that the highest value for this test was recorded at $334.82 \%$ by using CFA. This value is greater than the other five filler materials used in the formation of medium voltage cables. Elongation at break increased by $50 \%$ by using CFA. However, the highest value was $378.41 \%$ using quartz fine powder (QFP). For clay material, tensile strength and elongation at break were higher, as increasing the loading filler material creates more surface area of clay as compared to other filler materials [30]. Figure 7D shows the volume resistivity test result of insulated 
cables by using different fillers in the recipe. The highest peak value was recorded as $3 \times 10^{16}(\Omega \cdot \mathrm{cm})$ using 700-degree medium pressure clay (MPC), and the lowest peak value recorded was $1.7 \times 10^{16}$ $(\Omega \cdot \mathrm{cm})$ using 980 -degree low-pressure clay (LPC). However, the value for fly ash was recorded at $2.2 \times 10^{16}(\Omega \cdot \mathrm{cm})$, which was greater than the two main filler expensive filler materials, 980-degree low-pressure clay (LPC) and coal-based calcined high-pressure clay (refining type) (CBCHPC). Thus, the result described that fly ash can be used in the insulated cables' recipe instead of other expensive filler material.
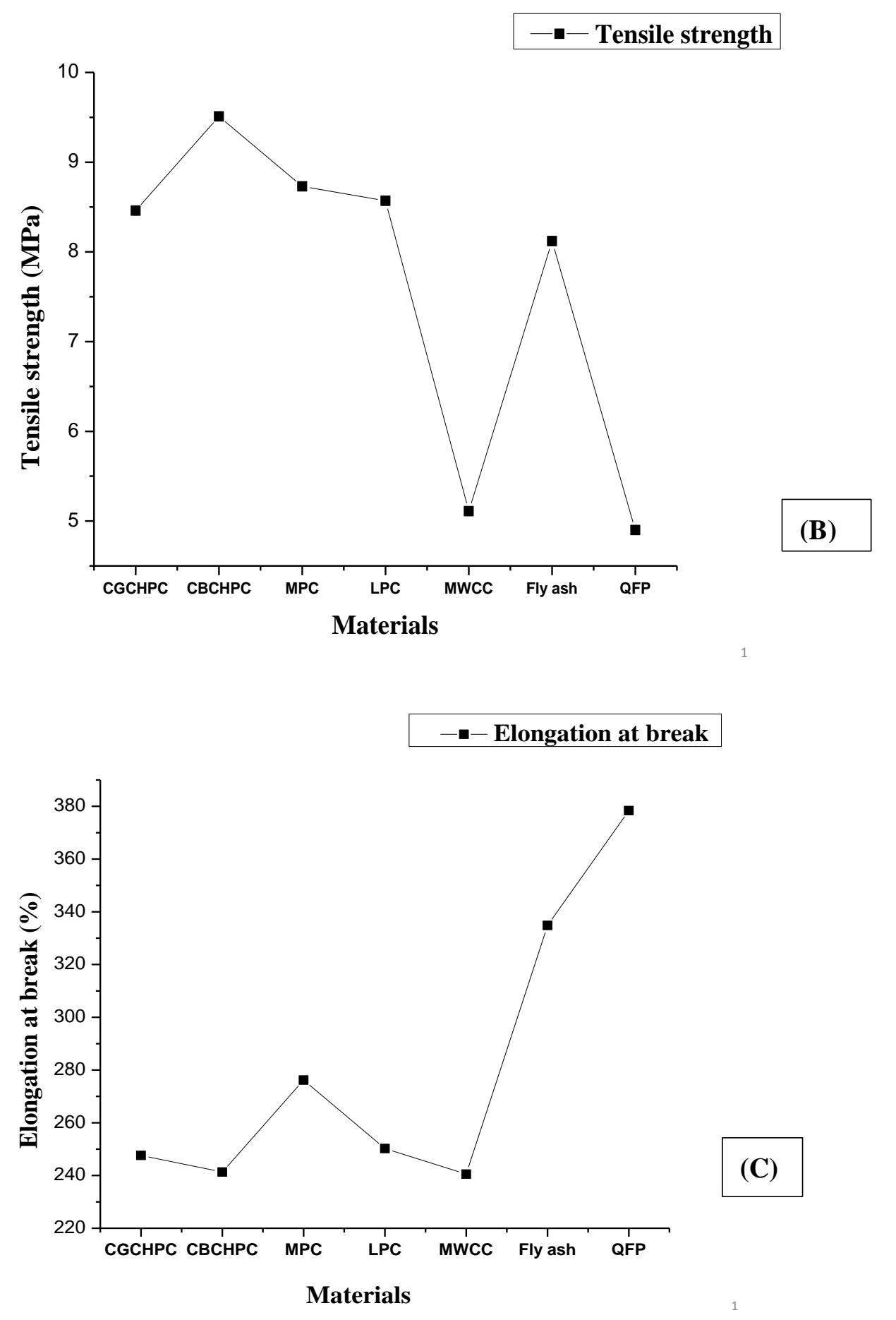

Figure 7. Cont. 


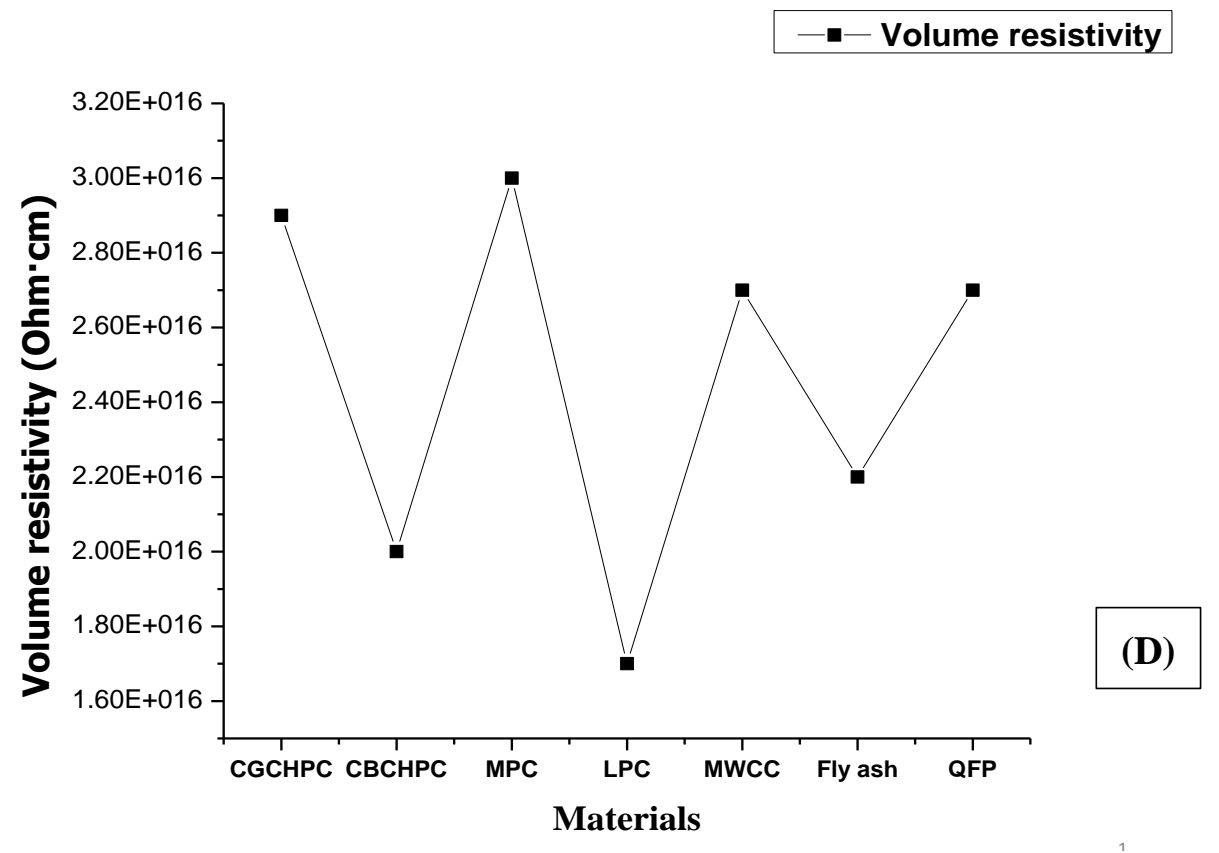

Figure 7. Comparison of different tests of fly ash with varying materials of filler in the production of medium voltage insulated cable. Thickness mm (A), Tensile strength MPa (B), Elongation at break \% (C), Volume resistivity Ohm-cm (D).

Figure $8 \mathrm{~A}$ shows the results of the outer diameter of the copper sheath. According to the national standard, $18.4 \pm 0.05 \mathrm{~mm}$ is the benchmark. The measured result for the test fly ash was very close, $18.37 \mathrm{~mm}$ and perfect as the national standard. Magnesium and kaolin magnesia results were also better, but a lower value was recorded for the talcum powder and magnesium oxide test, which was $17.98 \mathrm{~mm}$. It was found that talcum powder and magnesium oxide were more expensive than fly ash, and the results of the outer diameter as filler in fire resistance cable were not good and less than the standard value. Figure $8 \mathrm{~B}$ shows the result of the $20^{\circ} \mathrm{C}$ copper sheath $\mathrm{DC}$ resistance test. The national standard $(\leq 0.479 \Omega)$ was used. According to the national standard, fly ash and magnesium oxide filler results were better than other fillers at $0.386 \Omega$. DC resistance depends on conductor materials. It means that fly ash with magnesium oxide can be used instead of talcum powder and other materials. If the insulation part of the fire resistance cable quality is not good and has a lower thickness, then direct current resistance will also be affected. The study found that the thickness of the insulation part produced by CFA was better than other materials, and ultimately, DC resistance was also better than other expensive filler materials. Fly ash was also used as an alternative to carbon black in styrene-butadiene rubber (SBR) composites. Nano particle-sized fly ash (148 nm) had a major reinforcing effect instead of carbon black (CB), encouraged silica, or untreated fly debris $(60-100 \mu \mathrm{m})$ as uncovered by a higher modulus, rigidity, and hardness [24]. 

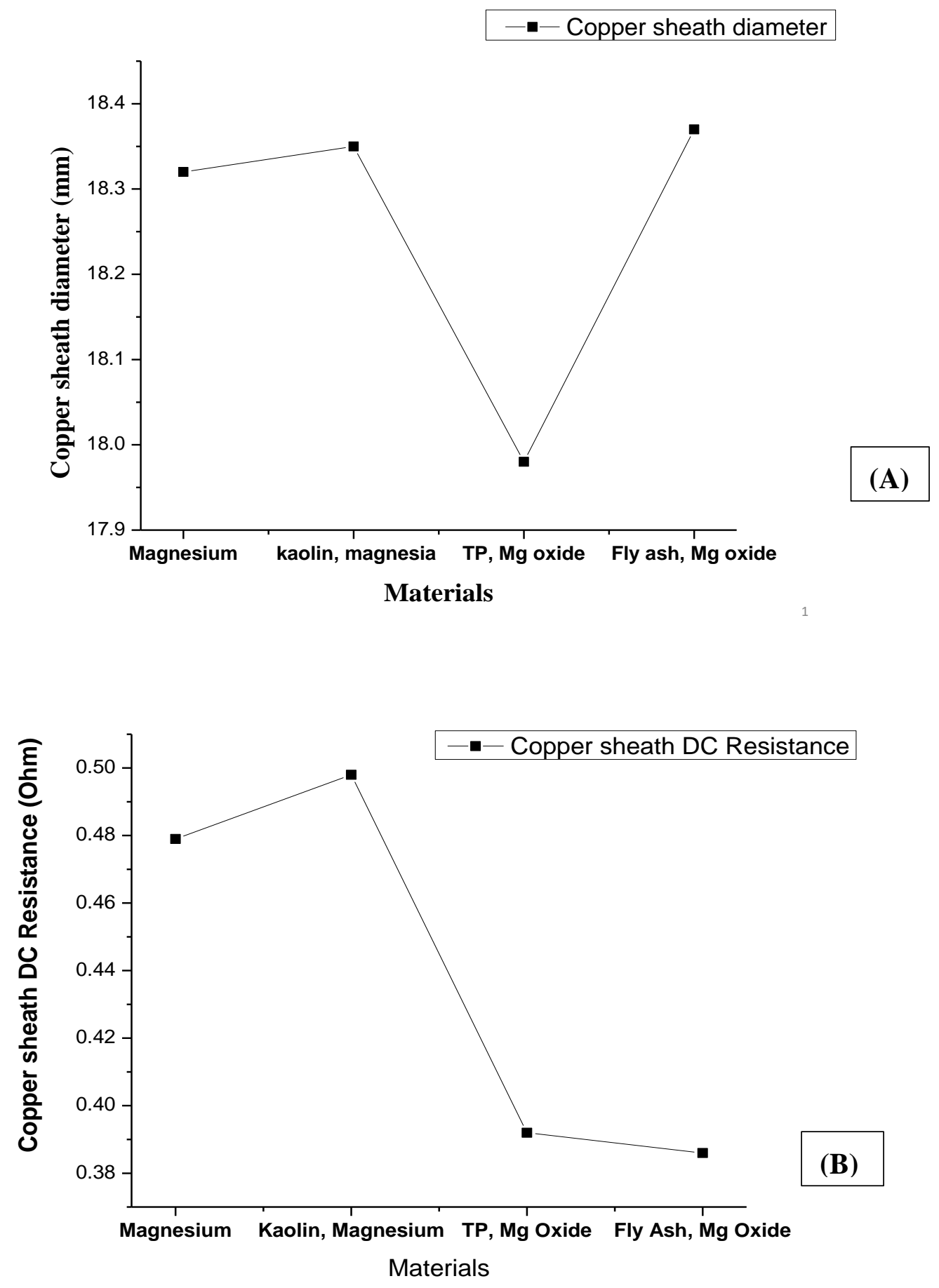

Figure 7. Cont. 

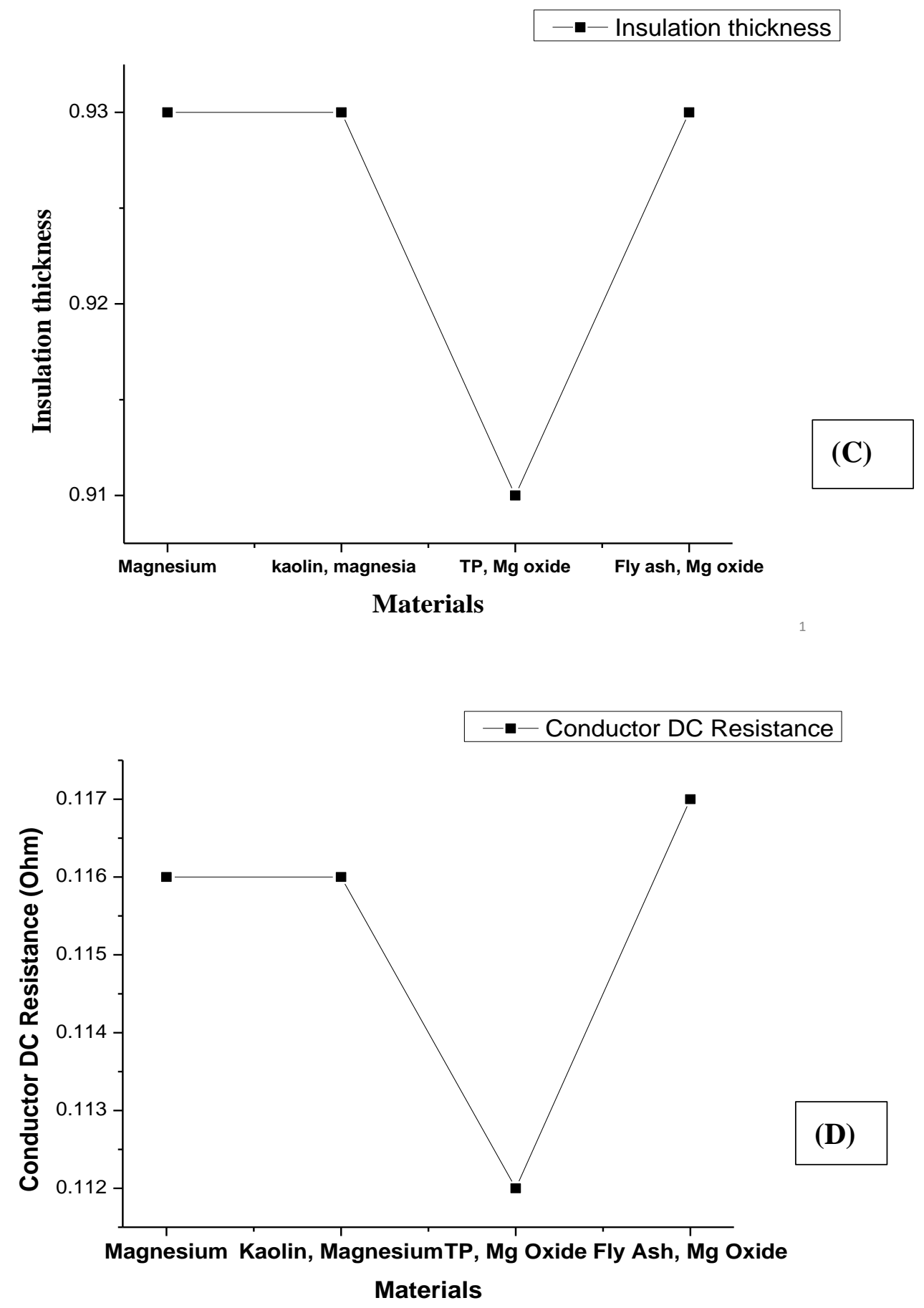

Figure 7. Cont. 

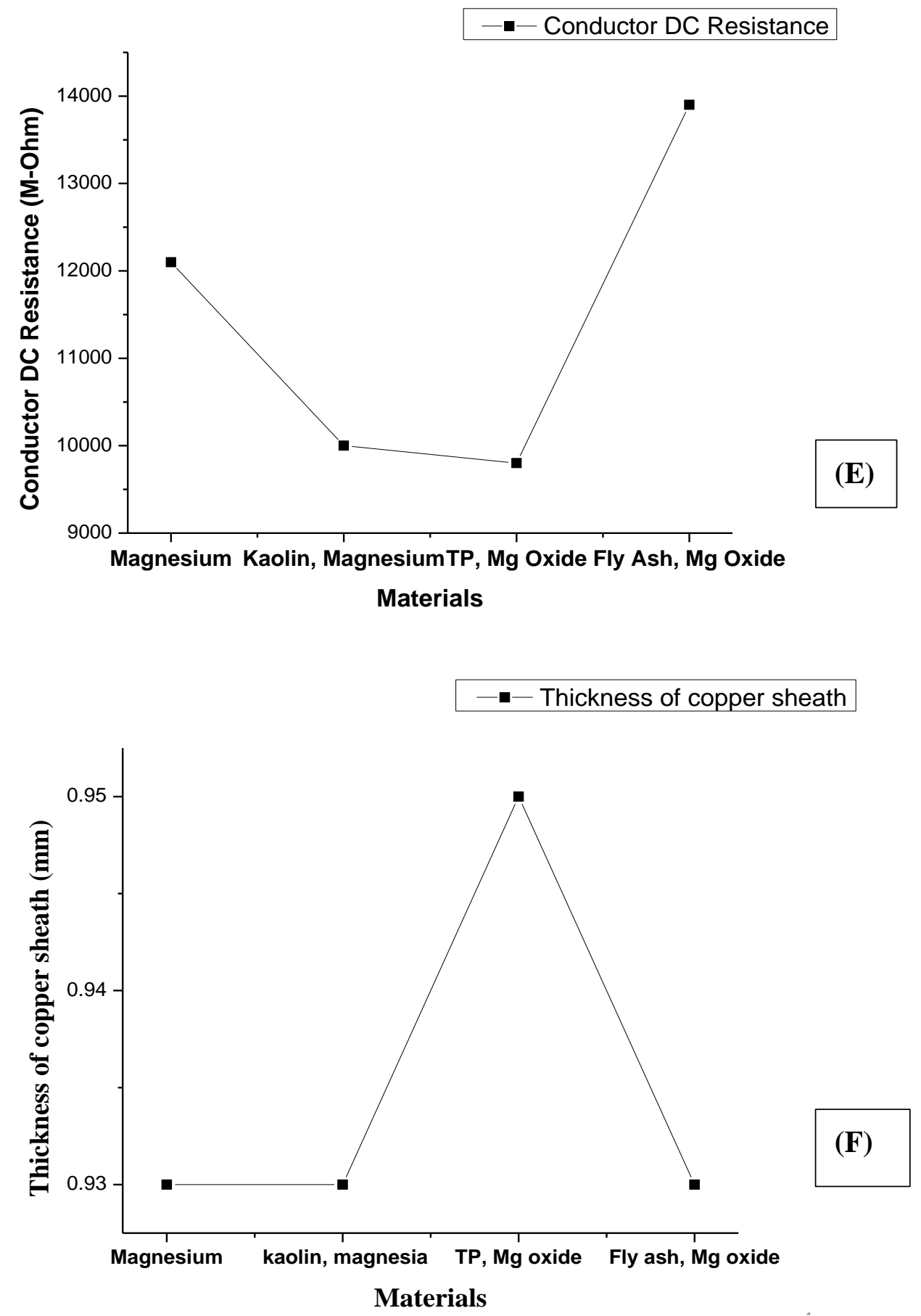

Figure 8. Comparison of different tests of fly ash with varying materials of filler in the production of fire resistant cables. (A) Copper sheath diameter mm, (B) Copper sheath DC resistance Ohm $/ \mathrm{km}$, (C) Insulation thickness mm, (D) Conductor DC resistance, (E) Insulation resistance M $\Omega$, (F) Thickness of copper sheath.

Figure $8 \mathrm{C}$ shows the result of the minimum insulation thickness. According to the national standard, the requirement of this test is $0.94 \mathrm{~m}$. Three different filler materials' results were the same and close to the standard and included fly ash and magnesium oxide filler, which was $0.93 \mathrm{~m}$. However, the talcum powder result was lower $(0.91 \mathrm{~m})$. So, if the talcum powder is used as a filler material in fire resistance cables, due to its thickness, it will also affect the DC resistance. Therefore, fly ash filler applied in fire resistance cables is better than talcum powder filler. Figure 8D shows the result of the $20{ }^{\circ} \mathrm{C}$ conductor DC resistance test. The national standard of this test is $\leq 0.124 \Omega$. 
The minimum value of this test was recorded at $0.112 \Omega$, which was found for talcum powder and magnesium oxide. The maximum value $(0.117 \Omega$ ) was recorded for the fly ash and magnesium oxide filler. The results of all four fillers were promising and can be used in making fire resistance cables. In addition, fly ash is cheaper than other materials, and applications of fly ash are also remarkable. The surface resistivity level is directly proportional to fly ash quantity. When the fly ash quantity in silicon rubber was increased, the test material results were also increased in the following measurement results, namely FA20 (Fly ash 20\%) was $6.7 \mathrm{G} \mathrm{Ohm/sq,} \mathrm{FA30} \mathrm{(Fly} \mathrm{ash} \mathrm{30 \% )} \mathrm{was} 8.4 \mathrm{G}$ Ohm/sq., FA40 (Fly ash $40 \%$ ) was $9.1 \mathrm{G} \mathrm{Ohm/sq.,} \mathrm{and} \mathrm{FA50} \mathrm{(Fly} \mathrm{ash} \mathrm{50 \% )} \mathrm{was} 11.4 \mathrm{G} \mathrm{Ohm/sq.}$

Figure $8 \mathrm{E}$ shows the test results of insulation resistance, which is an important measure and prevents electric shocks, and has a $\geq 10,000 \mathrm{M} \Omega$ standard. The highest value recorded was $13,900 \mathrm{M} \Omega$, which was for fly ash and magnesium oxide as filler materials. The minimum value recorded was $9800 \mathrm{M} \Omega$ using talcum powder and magnesium oxide. Insulation resistance protects the fire resistance cables from fire. If this insulation part of cable resistance is not according to the standard, it cannot be used in important buildings, such as hospitals, airports. So that test result showed that fly ash is a promising filler material to use in fire resistance cables.

Consequently, fly ash results were better than talcum powder. Moreover, fly ash is a cheaper and waste material, so it can be used as filler material. Figure $8 \mathrm{~F}$ shows the results of the average thickness of the copper sheath and has a $0.90 \mathrm{~mm}$ required national standard value. According to three filler materials, test results were the same, $0.93 \mathrm{~mm}$, including fly ash and magnesium oxide filler material, but the talcum powder and magnesium oxide value $(0.95 \mathrm{~mm})$ was greater than the others, which exceeded the standard value.

\section{Conclusions}

Overall results concluded that by applying CFA in insulated cables, elongation at break was increased by $50 \%$, volume resistance $2.2 \times 10^{16}(\Omega \cdot \mathrm{cm})$, and there was a better flame retardant effect using CFA in the insulated cable. This is due to fly ash bonding with other elements as silica has anionic properties that have strong bond strength and hold the element. Insulation resistance increased by $70 \%$ by using CFA with magnesium in the recipe of insulated cables. Fly ash results were better in insulated cables because it controls the temperature and humidity, which are very important factors for insulation resistance. Different test results for fly ash used in the formation of electrical cables showed that, by using this material as filler, crack problems, permeability, reduced heat of hydration and temperature and humidity can be controlled. Fly ash test results were better in fire resistance cables as insulation resistance was highest $(13,900 \mathrm{M} \Omega$ ) by using treated CFA. For making microparticles of CFA by using nozzle-based technology, the collection rate of cleaning ash was increased by $30 \%$, and the anti-clogging function, product life expectancy increased by $5-20 \%$.

Author Contributions: First author Z.H. did the research, collected the data, and wrote the paper with all methodology and results finalized, and the paper was checked and analyzed by G.L.; M.M. applied software, such as Origin, etc., to the data. All authors have read and agreed to the published version of the manuscript.

Funding: There was no funding provided for this research; this research was done with the help of the Ph.D. supervisor.

Acknowledgments: I would like to thank my supervisor (Gao Lizhen) and the Shanxi coal power plant, who provide me with coal fly ash for my research, and I also thank the Pengyi laboratory in China which help me by providing the testing facility.

Conflicts of Interest: The author declares no conflict of interest. 


\section{References}

1. Yunusa, I.A.M.; Loganathan, P.; Nissanka, S.P.; Manoharan, V.; Burchett, M.D.; Skilbeck, C.; Derek Eamus, D. Application of coal fly ash in agriculture: A strategic perspective. Crit. Rev. Environ. Sci. Technol. 2007, 42, 559-600. [CrossRef]

2. Shaheen, S.M.; Hooda, P.S.; Tsadilas, C.D. Opportunities and challenges in the use of coal fly ash for soil improvements: A review. J. Environ. Manag. 2014, 145, 249-267. [CrossRef]

3. Kishor, P.; Ghosh, A.K.; Kumar, D. Use of flyash in agriculture; a way to improve soil fertility and its productivity. Asian J. Agric. Res. 2010, 4, 1-14. [CrossRef]

4. Singh, R.P.; Sharma, B.; Sarkar, A.; Sengupta, C.; Singh, P.; Ibrahim, M.H. Biological responses of agricultural soils to fly-ash amendment. Rev. Environ. Contam. Toxicol. 2014, 232, 45-60. [CrossRef]

5. World Coal Association. Coal Statistics. Available online: http://www.worldcoal.org/resources/coal-statistics/ (accessed on 15 February 2010).

6. Sahu, G.; Bag, A.G.; Chatterjee, N.; Mukherjee, A.K. Potential use of fly ash in agriculture: A way to improve soil health. J. Pharm. Phytochem. 2017, 6, 873-880.

7. Feuerborn, H.J. Coal combustion products in Europe-An update on production and utilization, standardization and regulation. In Proceedings of the World Coal Ash Conference (WOCA), Denver, CO, USA, 9-12 May 2011. Available online: http://www.flyash.info/2011/007-feuerborn-2011.pdf (accessed on 22 June 2020).

8. Ren, X.; Sancaktar, E. Use of fly ash as eco-friendly filler in synthetic rubber for tire applications. J. Clear Prod. 2018, 206, 374-382. [CrossRef]

9. Ram, L.C.; Masto, R.E. Fly ash for soil amelioration: A review on the influence of ash blending with inorganic and orgamc amendments. Earth Sci. Rev. 2014, 128, 52-74. [CrossRef]

10. Pandey, V.C.; Singh, N. Impact of fly ash incorporation in soil systems. Agric. Ecosyst. Environ. 2010, 136, 16-27. [CrossRef]

11. Ukwattage, N.L.; Ranjith, P.G.; Bouazza, M. The use of coal combustion fly ash as a soil amendment in agricultural lands (with comments on its potential to improve food security and sequester carbon). Fuel 2013, 109, 400-408. [CrossRef]

12. Dhadse, S.; Kumari, P.; Bhagia, L.J. Fly ash characterization and utilization and government initiatives in India: A review. J. Sci. Ind. Res. 2008, 67, 11-18.

13. Huo, P.; Yan, Y.; Li, S.; Li, H.; Huang, W. Preparation and characterization of Cobalt Sulfophthalocyanine/ $\mathrm{TiO}_{2} /$ fly-ash cenospheres photocatalyst and study on degradation activity under visible light. Appl. Surf. Sci. 2009, 255, 6914-6917. [CrossRef]

14. Wu, C.; Yu, H.; Zhang, H. Extraction of aluminium by pressure acid-leaching method from fly ash. Trans. Nonferr. Met. Soc. China 2012, 22, 2282-2288. [CrossRef]

15. Yavuz, C.T.; Prakash, A.; Mayo, J.T.; Colvin, V.L. Magnetic separations: From steel plants to biotechnology. Chem. Eng. Sci. 2009, 64, 2510-2521. [CrossRef]

16. Tolhurst, L. Commercial recovery of metals from coal ash. In Proceedings of the World Coal Ash Conference (WOCA), Nashville, TN, USA, 5-7 May 2015. Available online: http://www.flyash.info/ (accessed on 22 June 2020).

17. Zhang, F.S.; Itoh, H. Extraction of metals from municipal solid waste incinerator fly ash by hydrothermal process. J. Haz. Mater. 2006, 136, 663-670. [CrossRef]

18. Blissett, R.S.; Rowson, N.A. A review of the multi-component utilization of coal fly ash. Fuel 2012, 97, 1-23. [CrossRef]

19. Gençoğlu, M.T. The comparison of ceramic and non-ceramic insulators. Eng. Sci. 2007, 2, $274-294$.

20. Fernando, M.A.R.M.; Gubanski, S.M. Ageing of silicone rubber insulators in coastal and inland tropical environment. IEEE Trans. Dielectr. Elec. Insul. 2010, 17, 326-333. [CrossRef]

21. Manjang, S.; Nagao, M. Characteristics of high voltage polymer insulator under accelerated artificial tropical climate multi stress aging. In Proceedings of the International Symposium on Electrical Insulating Materials, Kyoto, Japan, 6-10 September 2011; pp. 221-224.

22. Amin, M.; Amin, S.; Ali, M. Monitoring of leakage current for composite insulators and electrical devices. Rev. Adv. Mater. Sci. 2009, 21, 75-89. 
23. Siddique, R.; Kaur, G. Strength and permeation properties of self-compacting concrete containing fly ash and hooked steel fibers. Constr. Build. Mater. 2016, 103, 15-22. [CrossRef]

24. Paul, T.K.; Pabi, S.K.; Chakrabolty, K.K.; Nando, G.B. Nanostructured fly ash-styrene butadiene rubber hybrid nanocomposites. Polym. Compos. 2009, 30, 1647-1656. [CrossRef]

25. Chancey, R.T.; Stutzman, P.; Juenger, M.C.; Fowler, D.W. Comprehensive phase characterization of crystalline and amorphous phases of a Class F fly ash. Cem. Conc. Res. 2010, 40, 146-156. [CrossRef]

26. Parise, G.; Martirano, L.; Nabours, R.E. Arc-fault protection of branch circuits, cords, and connected equipment. IEEE Trans. Ind. Appl. 2004, 40, 896-899. [CrossRef]

27. Runyan, G.L.; Harrinton, B.A.; Chapman, B.R.; Dunaway, D.B.; Allenmann, G.A.; Russell, R.G.; Mize, R. Crosslinked Polyethylene Articles and Processes to Produce Same. U.S. Patent No. 8,192,813, 12 August 2002.

28. Ahmad, A.; Prayitno, A.; Satoto, R. Morphology and mechanical properties of palm based fly ash reinforced dynamically vulcanized natural rubber/polypropylene blends. Proc. Chem. 2012, 4, 146-153.

29. Ramesan, M.T. Processing characteristics and mechanical and electrical properties of chlorinated styrene-butadiene rubber/fly ash composites. J. Thermoplast. Compos. Mater. 2015, 28, 1286-1300. [CrossRef]

30. Gupta, T.; Chaudhary, S.; Sharma, R.K. Assessment of mechanical and durability properties of concrete containing waste rubber tire as fine aggregate. Constr. Build. Mater. 2014, 73, 562-574. [CrossRef]

(C) 2020 by the authors. Licensee MDPI, Basel, Switzerland. This article is an open access article distributed under the terms and conditions of the Creative Commons Attribution (CC BY) license (http://creativecommons.org/licenses/by/4.0/). 